Marquette University

e-Publications@Marquette

$12-5-2019$

\title{
Composition Effect on the Carrier Dynamics and Catalytic Performance of CulnS2/ZnS Quantum Dots for Light Driven Hydrogen Generation
}

Wenhui Hu

Marquette University

Sizhuo Yang

Marquette University

Jier Huang

Marquette University, jier.huang@marquette.edu

Follow this and additional works at: https://epublications.marquette.edu/chem_fac

Part of the Chemistry Commons

\section{Recommended Citation}

$\mathrm{Hu}$, Wenhui; Yang, Sizhuo; and Huang, Jier, "Composition Effect on the Carrier Dynamics and Catalytic Performance of CulnS2/ZnS Quantum Dots for Light Driven Hydrogen Generation" (2019). Chemistry Faculty Research and Publications. 1003.

https://epublications.marquette.edu/chem_fac/1003 


\title{
Composition effect on the carrier dynamics and catalytic performance of CulnS $2 / Z n S$ quantum dots for light driven hydrogen generation
}

Cite as: J. Chem. Phys. 151, 214705 (2019); doi: 10.1063/1.5125024

Submitted: 20 August 2019 - Accepted: 13 November 2019 •

Published Online: 5 December 2019

Wenhui Hu, Sizhuo Yang, and Jier Huang

\section{AFFILIATIONS}

Department of Chemistry, Marquette University, Milwaukee, Wisconsin 53201, USA

Note: This paper is part of the JCP Special Topic on Colloidal Quantum Dots.

a) Author to whom correspondence should be addressed: jier.huang@marquette.edu

\begin{abstract}
Water soluble $\mathrm{CuInS}_{2} / \mathrm{ZnS}$ quantum dots (QDs) represent one of the most promising single component photocatalysts for the hydrogen evolution reaction (HER). In this work, we report the effect of cation composition in $\mathrm{CuInS}_{2} / \mathrm{ZnS}$ QDs on the carrier relaxation and charge separation dynamics as well as their photocatalytic performance for the HER. With decreasing Cu to In ratio (increasing Cu deficiency), we observed slightly faster electron trapping and carrier recombination but significantly improved photocatalytic activity for the HER. This can be attributed to the enhanced electron transfer (ET) from the sacrificial donor to $\mathrm{CuInS}_{2} / \mathrm{ZnS}$ QDs resulting from the lower valence band (larger driving force for ET) of QDs with higher Cu deficiency. This work not only provides important insight into the mechanistic origins of the HER but also demonstrated that altering the composition in $\mathrm{CuInS}_{2} / \mathrm{ZnS}$ QDs is a viable approach to further improve their performance for solar to fuel conversion.
\end{abstract}

Published under license by AIP Publishing. https://doi.org/10.1063/1.5125024

\section{INTRODUCTION}

The efficient conversion and storage of solar energy represent a promising approach to address the increased energy demand and environmental problems caused by the combustion of fossil fuels. $^{1-3}$ One attractive strategy for solar energy conversion is lightdriven water splitting to generate $\mathrm{H}_{2}$ based on semiconductor photocatalysts. ${ }^{4,5}$ Since the first report of light-driven photocatalytic $\mathrm{H}_{2}$ generation based on semiconductors, ${ }^{6,7}$ various semiconductor nanocrystals have been reported as photocatalytic materials. ${ }^{8-10}$ Among them, $\mathrm{CuInS}_{2}$ (CIS) quantum dots (QDs), known as colloidal semiconductor nanocrystals with low toxicity, have become one of the most promising semiconductor photocatalytic materials for $\mathrm{H}_{2}$ generation due to their large optical absorption coefficient, tunable bandgap, and high photostability. ${ }^{11-14}$ However, majority of CIS based systems reported are decorated with cocatalysts, where
CIS mainly serves as a photosensitizer. ${ }^{15-21}$ In contrast to these reports, we recently found that CIS/ZnS core/shell QDs alone can efficiently catalyze the $\mathrm{H}_{2}$ evolution reaction (HER) in an aqueous solution with an exceptionally long lifetime. ${ }^{22}$ While this finding demonstrated the promise of CIS/ZnS as a single-component photocatalyst for the HER, the solar-to- $\mathrm{H}_{2}$ quantum yield is quite low $(<1 \%)$. Given the promising properties of this single-component system for the HER, it is necessary to further explore this system to improve its quantum efficiency for $\mathrm{H}_{2}$ generation.

Previous studies have shown that one critical limitation of CIS QDs to their application in photovoltaics and photocatalysis is associated with the surface related defect states, which results in defect-induced nonradiative transition and poor emission quantum yield. $^{23-26}$ A number of experimental and theoretical studies have demonstrated that the surface defect states in CIS QDs can originate from sulfur vacancy $\left(\mathrm{V}_{\mathrm{S}}\right)$, copper site substituted by indium 
$\left(\mathrm{In}_{\mathrm{Cu}}\right)$, copper vacancy $\left(\mathrm{V}_{\mathrm{Cu}}\right)$, indium vacancy $\left(\mathrm{V}_{\mathrm{In}}\right)$, and indium site substituted by copper $\left(\mathrm{Cu}_{\text {In }}\right)$, where $\mathrm{V}_{\mathrm{S}}$ and $\mathrm{In}_{\mathrm{Cu}}$ act as the donors and $\mathrm{V}_{\mathrm{Cu}}, \mathrm{V}_{\text {In }}$, and $\mathrm{Cu}_{\text {In }}$ act as acceptors. ${ }^{22,27-29}$ In general, in $\mathrm{Cu}$ rich CIS QDs, the main transitions are from the conduction band to $\mathrm{V}_{\text {In }}$ or $\mathrm{Cu}_{\text {In }}$ and from $\mathrm{V}_{\mathrm{S}}$ to the valence band. In $\mathrm{Cu}$ deficiency CIS QDs, the main transitions should be from $\mathrm{V}_{\mathrm{S}}$ to $\mathrm{V}_{\mathrm{Cu}}$ and from $\mathrm{In}_{\mathrm{Cu}}$ to $\mathrm{V}_{\mathrm{Cu}} \cdot{ }^{30-32}$ These literature data suggested that the defect states in CIS are largely dependent on their composition, and altering the composition of CIS may serve as a viable approach to tune their photophysical properties and photocatalytic activity for the HER.

In this work, we report the effect of cation composition on the carrier dynamics, charge separation, and photocatalytic performance of CIS/ZnS QDs for light driven $\mathrm{H}_{2}$ generation in an aqueous solution, where the ratio of $\mathrm{Cu}$ to In cations was systematically varied. We show that decreasing $\mathrm{Cu}$ to In ratio (increasing $\mathrm{Cu}$ deficiency) leads to slightly faster electron-hole pair recombination but significantly enhanced photocatalytic performance for the HER. This can be explained by improved overall charge separation due to faster electron transfer (ET) from the sacrificial donor to CIS/ZnS QDs in the sample with higher $\mathrm{Cu}$ deficiency resulting from the more positive valence band edge.

\section{EXPERIMENTAL METHODS}

Chemicals and Materials. Copper(I) iodide (CuI, 98\%), indium(III) acetate $\left[\mathrm{In}\left(\mathrm{OOCCH}_{3}\right)_{3}, 99.99 \%\right.$ metals basis], 1dodecanethiol (DDT, 98\%), and toluene (anhydrous, 99.8\%) were purchased from Alfa Aesar. 1-octadecene (ODE) and oleylamine (OLA) were purchased from Sigma-Aldrich. The rest chemicals and solvents were purchased from VWR. All chemicals were used as received without further purification.

Synthesis of CIS/ZnS QDs. In a typical synthesis for CIS with a Cu:In ratio of $1: 2,{ }^{33} \mathrm{CuI}(10 \mathrm{mg}, 0.05 \mathrm{mmol}), \mathrm{In}(\mathrm{OAc})_{3}(29.2 \mathrm{mg}$, $0.1 \mathrm{mmol})$, and 1-dodecanethiol (DDT) $(5 \mathrm{ml})$ were mixed in a three-necked flask. The reaction mixture was degassed with $\mathrm{N}_{2}$ for $30 \mathrm{~min}$ at room temperature. After that, the mixture was heated to $150^{\circ} \mathrm{C}$ until a clear yellow solution was formed. Then, the mixture was heated to $230^{\circ} \mathrm{C}$ and kept at this temperature for $5 \mathrm{~min}$. For further growth of the $\mathrm{ZnS}$ shell, the $\mathrm{Zn}$ stock solution $(4 \mathrm{ml}$ ) (see below for details) was added dropwise into the reaction mixture, after which the mixture was heated to $240{ }^{\circ} \mathrm{C}$ and kept at this temperature for $1 \mathrm{~h}$. The zinc stock solution was prepared in advance by mixing $\mathrm{Zn}(\mathrm{OAc})_{2}(0.219 \mathrm{mg}, 1 \mathrm{mmol})$, oleylamine (OLA) $(1 \mathrm{ml})$, and $\mathrm{ODE}(3 \mathrm{ml})$ in a flask, which is followed by degassing with $\mathrm{N}_{2}$ for $30 \mathrm{~min}$ and heating to $100^{\circ} \mathrm{C}$ until a colorless solution was formed. The resulting CIS/ZnS QDs were precipitated out using acetone, followed by centrifuging and decanting the supernatant. Half of the obtained samples were dispersed in toluene for optical property measurement, while the other half were used to prepare water soluble CIS/ZnS QDs. To synthesize CIS/ZnS QDs with different $\mathrm{Cu}$ to In ratios (i.e., 1:5, 1:8, and 1:10), the amount of $\mathrm{CuI}$ was kept the same while the amount of the In source was varied.

The Synthesis of Water Soluble CIS/ZnS QDs. The water soluble CIS/ZnS QDs were prepared through ligand exchange procedure in the presence of mercaptopropionic acid (MPA). ${ }^{34}$ In a typical synthesis, $2 \mathrm{ml}$ of MPA, $3 \mathrm{ml}$ of $\mathrm{N}, \mathrm{N}$-dimethylformamide (DMF), and $100 \mathrm{mg}$ of CIS/ZnS QDs were added into a $25 \mathrm{ml}$ flask, and degassed with $\mathrm{N}_{2}$ for $30 \mathrm{~min}$. The mixture was then heated to $130{ }^{\circ} \mathrm{C}$ and kept at this temperature for $30 \mathrm{~min}$, which results in the formation of a clear solution. The CIS/ZnS was precipitated out by adding $40 \mathrm{ml}$ of 2-propanol and centrifugated at $6000 \mathrm{rpm}$ for $10 \mathrm{~min}$. The obtained MPA capped CIS/ZnS QDs were dispersed in $15 \mathrm{ml} \mathrm{H}_{2} \mathrm{O}$.

Photocatalytic Hydrogen Generation. All photocatalytic reactions were performed in a $11 \mathrm{ml}$ vial under the illumination of a $405 \mathrm{~nm}$ light-emitting diode (LED) ( $3 \mathrm{~mW}$ ). Typically, $0.1 \mathrm{ml}$ of the CIS/ZnS QD solution was mixed with ascorbic acid (AA) $(1.00 \mathrm{ml}$, $0.2 \mathrm{M}$ in $\left.\mathrm{H}_{2} \mathrm{O}, \mathrm{pH}=5\right)$ and $\mathrm{H}_{2} \mathrm{O}(2.9 \mathrm{ml})$ in a sample vessel. The vial was sealed, degassed with nitrogen, and transferred to photocatalysis apparatus. The amount of evolved hydrogen (taken from $200 \mu \mathrm{l}$ of the headspace of the vial) was quantified by using an Agilent 490 micro gas chromatograph (5 ̊̊ molecular sieve column).

Standard Characterization. Steady-state UV-visible absorption spectra were taken using an HP Agilent 8453 spectrophotometer (UV-Visible) and a Cary 5000 spectrometer (UV-Visible-NIR). Steady-state emission spectra and time-correlated single photon counting (TCSPC) lifetime were measured using a Photon Technology International QuantaMaster 40 spectrofluorometer. To collect the optical properties, the prepared water soluble CIS/ZnS sample solution was placed in a $10 \mathrm{~mm}$ cuvette. The steady-state emission spectra and TCSPC were collected with 0.1 OD absorption at $400 \mathrm{~nm}$. A Rigaku MiniFlex II diffractometer with $\mathrm{Cu}$ Ka radiation was used to collect X-ray diffraction (XRD) patterns. Energy dispersive X-ray (EDX) spectroscopy data were collected on a Hitachi S-4800 scanning electron microscope with an EDAX XM2-60S energy dispersive spectrometer.

Transient Absorption (TA) Spectroscopy Measurement. The TA setup is a bump and probe system which is based on a regenerative amplified Ti-Sapphire laser system (Solstice, $800 \mathrm{~nm},<100 \mathrm{fs}$ FWHM, $3.5 \mathrm{~mJ} /$ pulse $1 \mathrm{kHz}$ repetition rate). The traveling-wave optical parametric amplifier of white-light continuum (TOPAS prime) will generate the tunable pump $(235-1100 \mathrm{~nm})$ with $75 \%$ of the output Ti-Sapphire laser. The sapphire window on a translation stage can generate the tunable UV-visible probe pulses (430$750 \mathrm{~nm}$ ) with the other $25 \%$ of the output Ti-Sapphire laser. The femtosecond TA measurements were performed in a Helios ultrafast spectrometer (Ultrafast Systems LLC). The prepared water soluble CIS/ZnS samples were placed in $2 \mathrm{~mm}$ cuvettes and all samples were under stirring during measurements to avoid multiexciton generation.

\section{RESULTS AND DISCUSSION}

Figure 1(a) shows the XRD patterns of CIS/ZnS with different $\mathrm{Cu}$ to In ratios. The $\mathrm{Cu}$ to In ratios of these samples were measured by EDX (Table S1) and were used to label these samples. All samples show three main peaks with $2 \theta$ values at $27.8^{\circ}, 46.9^{\circ}$, and $54.9^{\circ}$, which agree well with the literature data and support the formation of CIS/ZnS. ${ }^{35,36}$ Figure 1(b) shows the UV-visible absorption spectra of CIS/ZnS with four different ratios, which are featured by shoulder absorption bands at around $500 \mathrm{~nm}$ corresponding to the optical bandgap. ${ }^{37}$ With decreasing $\mathrm{Cu}$ to In ratio (increasing $\mathrm{Cu}$ deficiency), these absorption bands shift to a shorter wavelength, suggesting increasing bandgap between conduction and valence bands. Via the least-square fit of the linear region of a $(\mathrm{Ahv})^{2}$ vs 

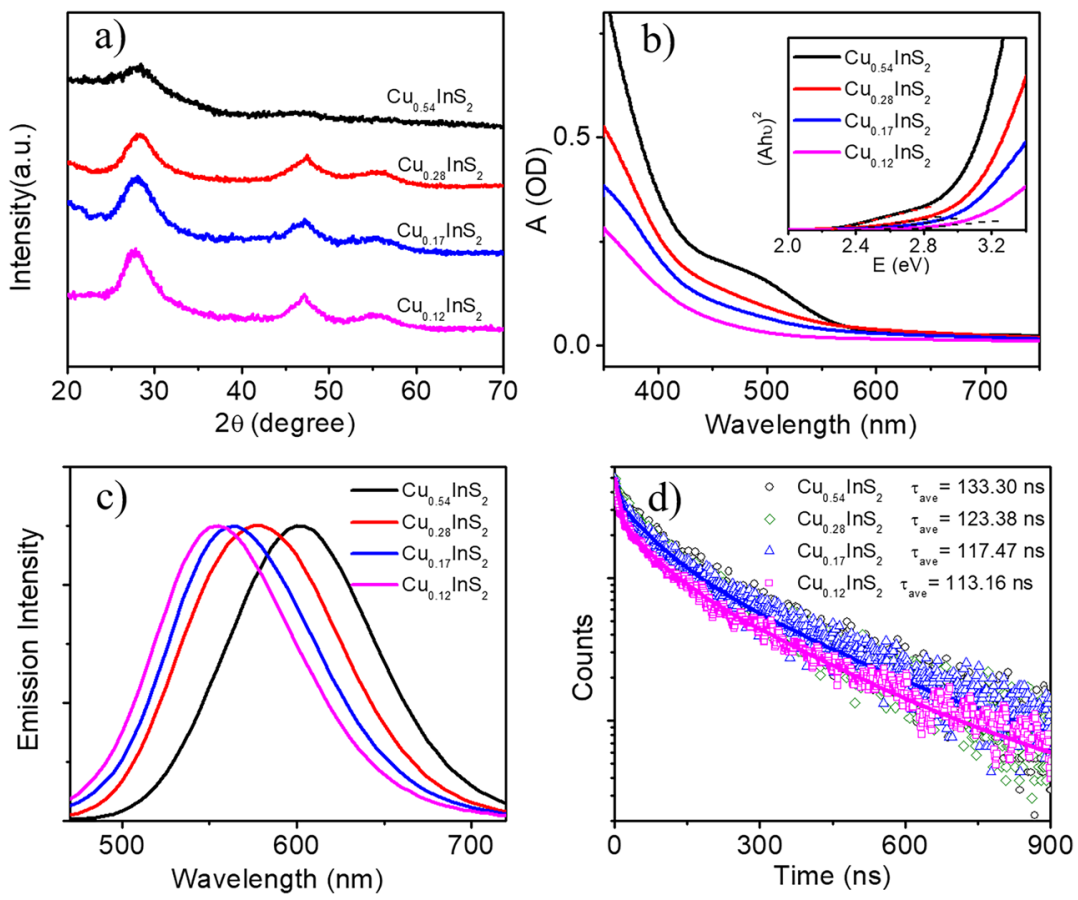

FIG. 1. XRD patterns (a), UV-visible absorption spectra (b), emission spectra (c), and emission lifetime decay kinetics (d) of CIS/ZnS QDs with different $\mathrm{Cu}$ to In ratios. The inset of (b) shows plots of $(A h v)^{2}$ vs energy to unravel the bandgap of CIS/ZnS QDs. The excitation wavelength for emission spectra and emission lifetime measurement is at $400 \mathrm{~nm}$. The probing wavelength is $600 \mathrm{~nm}, 580 \mathrm{~nm}$, $550 \mathrm{~nm}$, and $550 \mathrm{~nm}$ for samples with $\mathrm{Cu}_{0.54} \operatorname{lnS}{ }_{2}, \mathrm{Cu}_{0.28} \operatorname{lnS} \mathrm{S}_{2}, \mathrm{Cu}_{0.17} \mathrm{InS}_{2}$, and $\mathrm{Cu}_{0.12} \ln \mathrm{S}_{2}$, respectively. hv plot (A, absorbance; h, Planck's constant and $v$, frequency), the bandgaps of these CIS/ZnS QDs were estimated to be $2.25 \mathrm{eV}$, $2.40 \mathrm{eV}, 2.50 \mathrm{eV}$, and $2.65 \mathrm{eV}$ for QDs with $\mathrm{Cu}_{0.54} \mathrm{InS}_{2}, \mathrm{Cu}_{0.28} \mathrm{InS}_{2}$, $\mathrm{Cu}_{0.17} \mathrm{InS}_{2}$, and $\mathrm{Cu}_{0.12} \mathrm{InS}_{2}$, respectively [Inset of Fig. 1(b)].

In addition, the conduction band edges of these QDs were estimated by Mott-Schottky plots (Fig. S1), ${ }^{39}$ where a similar conduction band edge $(\sim 0.75 \mathrm{eV}$ vs $\mathrm{Ag} / \mathrm{AgCl})$ was obtained for these $\mathrm{CIS} / \mathrm{ZnS} \mathrm{QDs}$, suggesting that altering the $\mathrm{Cu}$ to In ratio within the 0.54:1 to $0.12: 1$ range has negligible impact on the conduction band edge. This also suggests that the change of bandgap with the $\mathrm{Cu}$ to In ratio is likely due to the shift of the valence band position, i.e., the valence band edge moves to more positive potential with increasing $\mathrm{Cu}$ deficiency. These results are consistent with previously reported data, ${ }^{40,41}$ suggesting the validity of the models we used to estimate the bandgap and conduction band edge.

The emission spectra of these samples following excitation at $400 \mathrm{~nm}$ are shown in Fig. 1(c). The emission peak position shifts from $600 \mathrm{~nm}$ to $554 \mathrm{~nm}$ with increasing $\mathrm{Cu}$ deficiency. This follows the same trend as their absorption spectra, further supporting that increasing $\mathrm{Cu}$ deficiency results in the increase of the bandgap of $\mathrm{CIS} / \mathrm{ZnS}$. The emission quantum yield (QY) is estimated to be $20 \%$, $11 \%, 9 \%$, and $8 \%$ for QDs with $\mathrm{Cu}_{0.54} \mathrm{InS}_{2}, \mathrm{Cu}_{0.28} \mathrm{InS}_{2}, \mathrm{Cu}_{0.17} \mathrm{InS}_{2}$, and $\mathrm{Cu}_{0.12} \mathrm{InS}_{2}$, respectively, which decreases with increasing $\mathrm{Cu}$ deficiency and suggests more defect states in the sample with higher $\mathrm{Cu}$ deficiency (Fig. S2). In order to gain insight into the average emission lifetime of CIS/ZnS QDs with different $\mathrm{Cu}$ to In ratios, the time resolved emission spectra of these samples were measured following $400 \mathrm{~nm}$ excitation. Figure 1 (d) shows the time-resolved emission lifetime decay kinetics of CIS/ZnS QDs with different $\mathrm{Cu}$ to In ratios. It can be seen that $\mathrm{Cu}_{0.12} \mathrm{InS}_{2}$ has the fastest decay, indicating the shortest average emission lifetime. The decay curves of the samples were fitted with a tri-exponential decay function,

$$
\mathrm{I}(\mathrm{t})=\mathrm{A}_{1} \exp \left(-\mathrm{t} / \tau_{1}\right)+\mathrm{A}_{2} \exp \left(-\mathrm{t} / \tau_{2}\right)+\mathrm{A}_{3} \exp \left(-\mathrm{t} / \tau_{3}\right),
$$

where $A_{1}, A_{2}$, and $A_{3}$ are fractional contributions of PL decay lifetimes of $\tau_{1}, \tau_{2}$, and $\tau_{3}$, respectively.

The fitting results are listed in Table S2. The obtained average lifetimes of these samples are $133.3 \mathrm{~ns}$ for $\mathrm{Cu}_{0.54} \mathrm{InS}_{2}, 123.4 \mathrm{~ns}$ for $\mathrm{Cu}_{0.28} \mathrm{InS}_{2}, 117.5 \mathrm{~ns}$ for $\mathrm{Cu}_{0.17} \mathrm{InS}_{2}$, and $113.2 \mathrm{~ns}$ for $\mathrm{Cu}_{0.12} \mathrm{InS}_{2}$, which shows that the emission lifetimes of these samples are similar to the minor trend showing decreasing emission lifetime with increasing $\mathrm{Cu}$ deficiency. These results also suggest that different $\mathrm{Cu}$ to In ratios in the CIS/ZnS QDs have negligible impact on electron-hole radiative recombination time.

The carrier recombination dynamics of CIS/ZnS QDs with different $\mathrm{Cu}$ to In ratios was further investigated using femtosecond transient absorption (TA) spectroscopy to unravel the early time carrier relaxation dynamics. The TA spectra of these samples were all collected under $400 \mathrm{~nm}$ excitation with $20 \mu \mathrm{J} / \mathrm{cm}^{2}$ power. Under this excitation power, the average number of exciton per QD is estimated to be 0.19 for $\mathrm{Cu}_{0.54} \mathrm{InS}_{2}$ (Fig. S3). ${ }^{42}$ Shown in Fig. 2 are the TA spectra of CIS/ZnS QDs, where the insets show the early time spectra. The TA spectra of all four CIS/ZnS QD samples were featured by a negative band and a broad positive absorption, where the former can be assigned to the exciton bleach band and the latter can be attributed to the electron absorption. ${ }^{22,43}$ It can be clearly seen that the exciton bleach band shifts to a shorter wavelength with increasing $\mathrm{Cu}$ deficiency, which is consistent with the UV-Vis absorption and emission results above. As shown in the insets of Fig. 2, the early time spectra $(<1 \mathrm{ps})$ for all four samples show an 

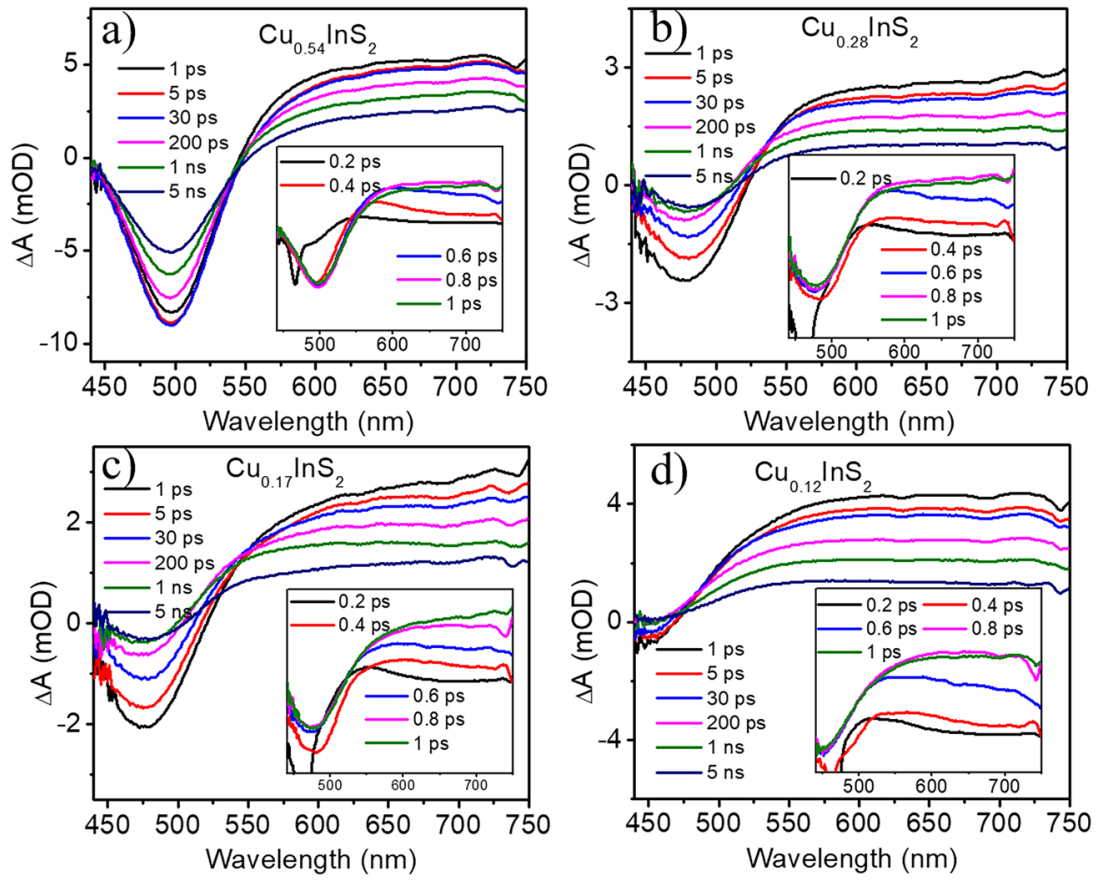

FIG. 2. Femtosecond transient absorption spectra of $\mathrm{CIS} / \mathrm{ZnS} \mathrm{QDs}$ with different $\mathrm{Cu}$ to In ratios: (a) $\mathrm{Cu}_{0.54} \operatorname{lnS} \mathrm{S}_{2}$ (b) $\mathrm{Cu}_{0.28} \operatorname{lnS} \mathrm{S}_{2} ; \quad$ (c) $\quad \mathrm{Cu}_{0.17} \operatorname{lnS} \mathrm{S}_{2} ; \quad$ (d) $\mathrm{Cu}_{0.12} \operatorname{lnS} \mathrm{S}_{2}$. The excitation wavelength is at $400 \mathrm{~nm}$. ultrafast rising component for the electron absorption signal. This component can be attributed to the electron trapping and/or cooling process, which is based on both the literature and our own experimental results. Previous data have shown that this rising component can be attributed to the electron trapping process, ${ }^{26,43-45}$ while our experiments show that the rising component disappears when $450 \mathrm{~nm}$ light was used as the excitation wavelength (Fig. S4), suggesting that the cooling process contributes to this rising component.

To further evaluate the carrier dynamics of these CIS/ZnS QDs, we compared the exciton bleach recovery and the kinetic traces of the electron absorption signals of these samples. The kinetic traces were normalized at a later time in order to have a better comparison for the early time kinetics. Due to the small signal of the exciton bleach band as well as the overlap between the exciton bleach and the electron absorption signal for $\mathrm{Cu}_{0.12} \mathrm{InS}_{2}$, we are not able to compare its early time spectral evolution for the exciton bleach signal with other samples. Nevertheless, the exciton bleach recovery of $\mathrm{Cu}_{0.54} \mathrm{InS}_{2}, \mathrm{Cu}_{0.28} \mathrm{InS}_{2}$, and $\mathrm{Cu}_{0.17} \mathrm{InS}_{2}$ becomes faster with increasing $\mathrm{Cu}$ deficiency, suggesting that the $\mathrm{Cu}$ deficiency can affect the electron-hole recombination process. This appears to conflict with emission lifetime measurement discussed above, where $\mathrm{Cu}$ deficiency has negligible impact on the electron-hole recombination time. This discrepancy can be explained by the different time windows those time resolved emission and absorption spectroscopies measure, where the former probes the recombination dynamics at $>10 \mathrm{~ns}$ window due to its limited time resolution ( $10 \mathrm{~ns})$, while the later measures the early time recombination dynamics at $<5 \mathrm{~ns}$ due to the limited time window of our TA spectroscopy. On the other hand, as shown in Fig. 3(b), the kinetic trace of the electron absorption decays slightly faster in the sample with higher $\mathrm{Cu}$
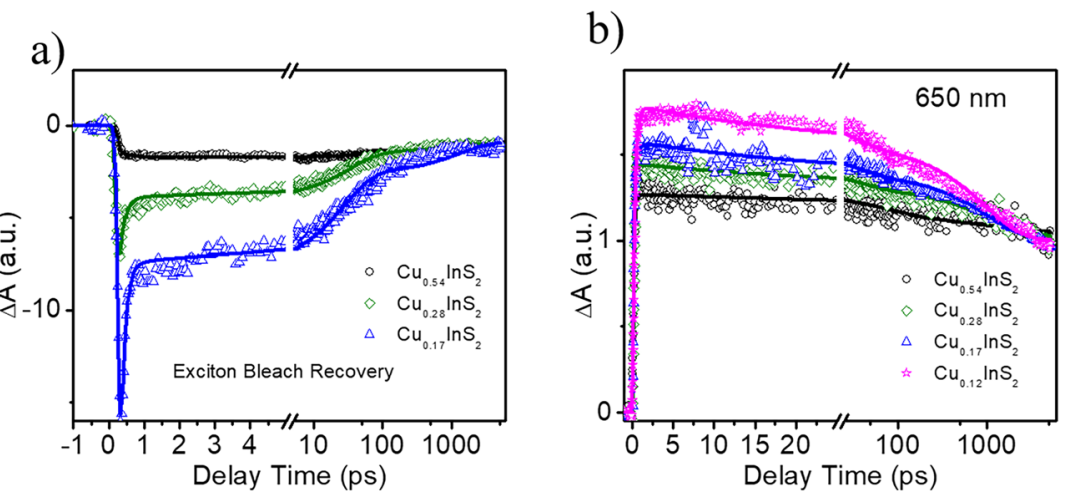

FIG. 3. (a) The comparison of exciton bleach recovery for $\mathrm{Cu}_{0.54} \ln \mathrm{S}_{2}$ $\mathrm{Cu}_{0.28} \mathrm{InS}_{2}$, and $\mathrm{Cu}_{0.17} \operatorname{lnS} \mathrm{S}_{2}$. (b) The comparison of kinetic traces of electron absorption decay of CIS/ZnS QDs at $650 \mathrm{~nm}$ with different $\mathrm{Cu}$ to $\mathrm{In}$ ratios. The excitation wavelength is at $400 \mathrm{~nm}$. 

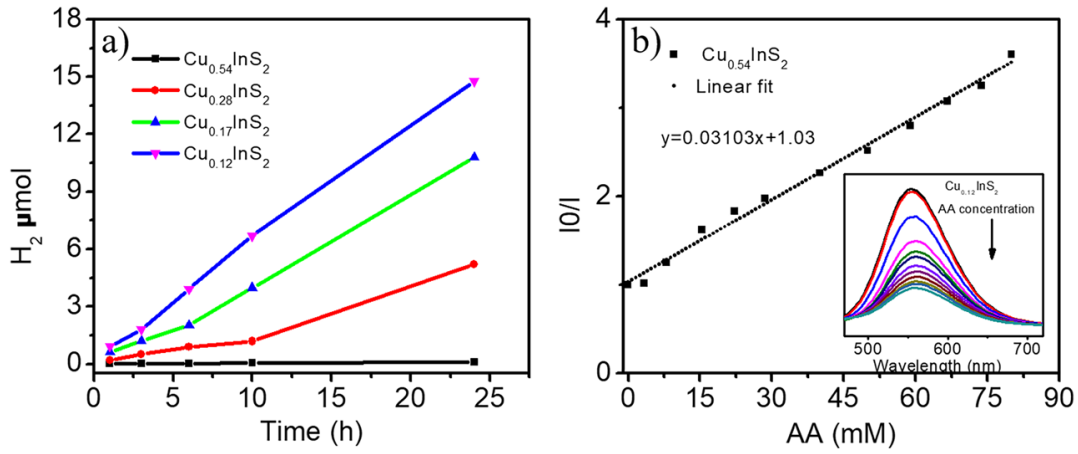

FIG. 4. (a) $\mathrm{H}_{2}$ generation time profile of $\mathrm{CIS} / \mathrm{ZnS}$ QDs with four different $\mathrm{Cu}$ to In ratios under $405 \mathrm{~nm}$ illumination with $3 \mathrm{~mW}$ power. AA is used as the proton source and sacrificial electron donor. (b) Stern-Volmer plot of $\mathrm{Cu}_{0.12} \mathrm{InS}_{2}$; inset: emission quenching spectra with $A A$ under $400 \mathrm{~nm}$ excitation. deficiency, which is consistent with the exciton bleach recovery. These results can be more clearly seen in the fitting results. As shown in Fig. 3 and Table S3, the kinetic traces of all samples can be fit by a four-exponential decay/rise function. Due to the presence of multiple carrier trapping states and recombination channels in CIS QDs, it is challenging to correlate each time constant with the relaxation pathway. However, according to the time scales of carrier trapping and recombination reported by previous studies, ${ }^{23,25,26,44}$ the ultrafast rising/decay component $\left(\tau_{1}\right)$ which is close to the instrument resolution limit $(\sim 0.2 \mathrm{ps})$ can be attributed to the electron cooling and/or trapping to the shallow electron trap states; $\tau_{2}$ is likely due to the additional carrier trapping by deep-level trap states, and $\tau_{3}$ and $\tau_{4}$ can be attributed to the recombination of the electrons from these trap states with the holes from the valence band. However, due to the presence of $\gg 5 \mathrm{~ns}$ time constant which is beyond the time window of our TA spectroscopy, we are not able to accurately determine the carrier recombination time. Nevertheless, since $\tau_{2}$ and $\tau_{3}$ decrease slightly with increasing $\mathrm{Cu}$ deficiency, it suggests that the recombination process is enhanced slightly in the sample with higher $\mathrm{Cu}$ deficiency.

To evaluate the correlation of the composition of CIS/ZnS QDs with their function for catalysis, we examined the catalytic performance of these samples for $\mathrm{H}_{2}$ generation under $405 \mathrm{~nm}$ LED irradiation. The sample container is a glass vial with $4 \mathrm{ml}$ reaction solution and $7 \mathrm{ml}$ head space. The reaction solution includes $1 \mathrm{ml}$ ascorbic acid (AA) $(\mathrm{pH}=5)$ as the electron donor, $0.1 \mathrm{ml}$ of CIS/ZnS aqueous solution ( $\sim 0.2 \mathrm{mg} \mathrm{CIS} / \mathrm{ZnS})$, and $2.9 \mathrm{ml} \mathrm{H}_{2} \mathrm{O}$. The glass vial was sealed with a rubber stopper and purged with $\mathrm{N}_{2}$ for at least 10 min before irradiation. Figure 4(a) shows the amount of $\mathrm{H}_{2}$ generated as a function of irradiation time. It can be clearly seen that the $\mathrm{H}_{2}$ generation efficiency increases significantly with the increasing $\mathrm{Cu}$ deficiency, where the amount of $\mathrm{H}_{2}$ generated for $\mathrm{Cu}_{0.12} \mathrm{InS}_{2}$ is almost 100 times higher than that of $\mathrm{Cu}_{0.54} \mathrm{InS}_{2}$. In order to have a valid comparison of the $\mathrm{H}_{2}$ generation efficiency among different CIS/ZnS QDs to account for the difference of absorbed photons under LED illumination (405 nm), we evaluated the $\mathrm{H}_{2}$ generation efficiency in terms of photon-to- $\mathrm{H}_{2}$ quantum yield according to the method published previously. ${ }^{46}$ The obtained photon-to- $\mathrm{H}_{2}$ quantum yields are $\ll 1 \%, 0.7 \%, 3.8 \%$, and $5.2 \%$ for the $\mathrm{Cu}_{0.54} \mathrm{InS}_{2}$, $\mathrm{Cu}_{0.28} \mathrm{InS}_{2}, \mathrm{Cu}_{0.17} \mathrm{InS}_{2}$, and $\mathrm{Cu}_{0.12} \mathrm{InS}_{2}$, respectively, which increases with increasing $\mathrm{Cu}$ deficiency. While higher photon-to- $\mathrm{H}_{2}$ quantum yields $(\sim 5 \%-20 \%)$ have been reported previously in colloidal photocatalytic systems, ${ }^{46-50}$ all of these systems include a cocatalyst that plays a major role in boosting the photocatalytic efficiency. To the best of our knowledge, CIS based photocatalytic systems without cocatalysts show a much lower photon-to- $\mathrm{H}_{2}$ quantum yield $(\leq 5 \%){ }^{22,51}$ Indeed, the photon-to- $\mathrm{H}_{2}$ quantum yield in our system with $\mathrm{Cu}_{0.12} \mathrm{InS}_{2}(5.2 \%)$ is slightly higher than that of the previously best-performing system (5\%). ${ }^{51}$ These results together suggest that the presence of $\mathrm{Cu}$ deficiency can significantly enhance the photocatalytic performance of CIS/ZnS QDs and altering the $\mathrm{Cu}$ to In ratio is a viable approach to further optimize the photocatalytic performance of CIS/ZnS QDs for the HER.

Note that CIS/ZnS QDs with higher Cu deficiency show slightly faster charge recombination but much better photocatalytic activity. This appears to conflict with the commonly accepted model, where the elongated electron-hole pair lifetime is beneficial for $\mathrm{H}_{2}$ generation. ${ }^{22,46,51,52}$ In order to gain insight into the origin of this conflict, we examined the electron transfer (ET) process from AA to CIS/ZnS QDs, which is another key pathway that determines the overall efficiency for $\mathrm{H}_{2}$ generation. Electron transfer from AA to CIS/ZnS QDs was evaluated by measuring the steady state emission quenching of CIS/ZnS QDs as a function of AA concentration followed by Stern-Volmer analysis. As shown in Fig. 4(b) and Fig. S6, we found that the ET rate constants are $0.58 \times 10^{8} \mathrm{M}^{-1} \mathrm{~S}^{-1}$, $1.02 \times 10^{8} \mathrm{M}^{-1} \mathrm{~S}^{-1}, 1.77 \times 10^{8} \mathrm{M}^{-1} \mathrm{~S}^{-1}$, and $2.74 \times 10^{8} \mathrm{M}^{-1} \mathrm{~S}^{-1}$ for QDs with $\mathrm{Cu}_{0.54} \mathrm{InS}_{2}, \mathrm{Cu}_{0.28} \mathrm{InS}_{2}, \mathrm{Cu}_{0.17} \mathrm{InS}_{2}$, and $\mathrm{Cu}_{0.12} \mathrm{InS}_{2}$, respectively, which increase considerably with increasing $\mathrm{Cu}$ deficiency, following the same trend as their photocatalytic performance. Combining the results from the carrier dynamics of CIS/ZnS QDs measured by TA spectroscopy, emission quenching experiment, and their photocatalytic performance for $\mathrm{H}_{2}$ generation, we believe that the ET from AA to CIS/ZnS QDs plays an important role in overall charge separation and catalytic activity for $\mathrm{H}_{2}$ generation, where the faster ET process in the sample with higher $\mathrm{Cu}$ deficiency results in more efficient overall charge separation and thus significantly enhanced photocatalytic performance. The faster ET in CIS/ZnS QDs with higher $\mathrm{Cu}$ deficiency may result from their lower valence band, which leads to a larger driving force for the ET to occur from AA to CIS/ZnS QDs.

\section{CONCLUSIONS}

In summary, we report the dependence of carrier and charge separation dynamics of CIS/ZnS QDs and their photocatalytic performance for light driven hydrogen generation on the cation composition (i.e., $\mathrm{Cu}$ to $\mathrm{In}$ ratio). With increasing $\mathrm{Cu}$ deficiency (decreasing $\mathrm{Cu}$ to In ratio), we show that the electron-hole pair 
recombination in CIS/ZnS QDs measured by TA spectroscopy is a little faster while the photocatalytic activities for $\mathrm{H}_{2}$ generation are significantly improved. This can be explained by the notably enhanced ET from AA to CIS/ZnS QDs resulting from the lower valence band edge of QDs (larger driving force for ET) for samples with higher $\mathrm{Cu}$ deficiency, which facilitates overall charge separation. This work suggests that altering the cation composition in CIS/ZnS QDs is a viable approach to further improve their photocatalytic performance for solar to fuel conversion.

\section{SUPPLEMENTARY MATERIAL}

See the supplementary material for the Mott-Schottky plots, kinetics comparison for each QD at different probe wavelengths, tables that list the fitting parameters for time resolved emission and absorption kinetic traces, and Stern-Volmer plots for emission quenching experiments.

\section{ACKNOWLEDGMENTS}

This work was supported by National Science Foundation (Grant No. DMR-1654140) and ACS-PRF (Grant No. 57503-DNI6). Sizhuo Yang and Wenhui Hu acknowledge the John J. Eisch fellowship during the 2018-2019 and 2019-2020 academic years, respectively.

\section{REFERENCES}

${ }^{1}$ M. Gratzel, Acc. Chem. Res. 14(12), 376-384 (1981).

${ }^{2}$ E. Fujita, Coord. Chem. Rev. 185-186, 373-384 (1999).

${ }^{3}$ Y. Yamazaki, H. Takeda, and O. Ishitani, J. Photochem. Photobiol., C 25, 106137 (2015).

${ }^{4}$ A. J. Bard and M. A. Fox, Acc. Chem. Res. 28(3), 141-145 (1995).

${ }^{5}$ I. Tsuji, H. Kato, and A. Kudo, Angew. Chem., Int. Ed. 44(23), 3565-3568 (2005).

${ }^{6}$ A. Fujishima and K. Honda, Nature 238(5358), 37-38 (1972).

${ }^{7}$ J. M. Lehn and J. P. Sauvage, New J. Chem. 1(6), 449-451 (1977).

${ }^{8}$ A. Mills, R. H. Davies, and D. Worsley, Chem. Soc. Rev. 22(6), 417-425 (1993).

${ }^{9}$ B. Oregan and M. Gratzel, Nature 353(6346), 737-740 (1991).

${ }^{10}$ X. B. Chen, S. H. Shen, L. J. Guo, and S. S. Mao, Chem. Rev. 110(11), 6503-6570 (2010).

${ }^{11}$ S. C. Lian, M. S. Kodaimati, D. S. Dolzhnikov, R. Calzada, and E. A. Weiss, J. Am. Chem. Soc. 139(26), 8931-8938 (2017).

${ }^{12}$ B. K. Chen, H. Z. Zhong, W. Q. Zhang, Z. A. Tan, Y. F. Li, C. R. Yu, T. Y. Zhai, Y. S. Bando, S. Y. Yang, and B. S. Zou, Adv. Funct. Mater. 22(10), 2081-2088 (2012).

${ }^{13}$ X. X. Li, K. Y. Xie, L. Song, M. J. Zhao and Z. P. Zhang, ACS Appl. Mater. Interfaces 9(29), 24577-24583 (2017).

${ }^{14}$ B. T. Zhang, Y. C. Wang, C. B. Yang, S. Y. Hu, Y. Gao, Y. P. Zhang, Y. Wang, H. V. Demir, L. W. Liub, and K. T. Yong, Phys. Chem. Chem. Phys. 17(38), 2513325141 (2015).

${ }^{15}$ K. T. Kuo, D. M. Liu, S. Y. Chen, and C. C. Lin, J. Mater. Chem. 19(37), 67806788 (2009)

${ }^{16}$ L. Zheng, Y. Xu, Y. Song, C. Z. Wu, M. Zhang, and Y. Xie, Inorg. Chem. 48(9), 4003-4009 (2009).

${ }^{17}$ I. Tsuji, H. Kato, H. Kobayashi, and A. Kudo, J. Phys. Chem. B 109(15), 73237329 (2005)

${ }^{18}$ Y. J. Yuan, D. Q. Chen, Y. W. Huang, Z. T. Yu, J. S. Zhong, T. T. Chen, W. G. Tu, Z. J. Guan, D. P. Cao, and Z. G. Zou, ChemSusChem 9(9), 1003-1009 (2016).

${ }^{19}$ A. Iwase, S. Yoshino, T. Takayama, Y. H. Ng, R. Amal, and A. Kudo, J. Am. Chem. Soc. 138(32), 10260-10264 (2016).
${ }^{20}$ K. Iwashina, A. Iwase, Y. H. Ng, R. Amal, and A. Kudo, J. Am. Chem. Soc. 137(2), 604-607 (2015).

${ }^{21}$ H. Kaneko, T. Minegishi, M. Nakabayashi, N. Shibata, Y. B. Kuang, T. Yamada, and K. Domen, Adv. Funct. Mater. 26(25), 4570-4577 (2016).

${ }^{22}$ Y. L. Zhou, W. H. Hu, J. Ludwig, and J. Huang, J. Phys. Chem. C 121(35), 19031-19035 (2017).

${ }^{23}$ D. H. Jara, K. G. Stamplecoskie, and P. V. Kamat, J. Phys. Chem. Lett. 7(8), 1452-1459 (2016).

${ }^{24}$ A. D. P. Leach and J. E. Macdonald, J. Phys. Chem. Lett. 7(3), 572-583 (2016).

${ }^{25}$ R. Bose, G. H. Ahmed, E. Alarousu, M. R. Parida, A. L. Abdelhady, O. M. Bakr, and O. F. Mohammed, J. Phys. Chem. C 119(6), 3439-3446 (2015).

${ }^{26}$ P. H. Chuang, C. C. Lin, and R. S. Liu, ACS Appl. Mater. Interfaces 6(17), 15379-15387 (2014).

${ }^{27}$ H. Ueng and H. Hwang, J. Phys. Chem. Solids 50(12), 1297-1305 (1989).

${ }^{28}$ J. Binsma, L. Giling, and J. Bloem, J. Lumin. 27(1), 35-53 (1982).

${ }^{29}$ T. Omata, K. Nose, K. Kurimoto, and M. Kita, J. Mater. Chem. C 2(33), 68676872 (2014).

${ }^{30}$ K. Nose, T. Omata, and S. Otsuka-Yao-Matsuo, J. Phys. Chem. C 113(9), 34553460 (2009).

${ }^{31}$ T. Debnath, S. Maiti, P. Maity, and H. N. Ghosh, J. Phys. Chem. Lett. 6(17), 3458-3465 (2015).

${ }^{32}$ S. B. Zhang, S. H. Wei, A. Zunger, and H. Katayama-Yoshida, Phys. Rev. B 57(16), 9642-9656 (1998).

${ }^{33}$ B. Huang, Q. Dai, N. Z. Zhuo, Q. S. Jiang, F. H. Shi, H. B. Wang, H. C. Zhang, C. Liao, Y. P. Cui, and J. Y. Zhang, J. Appl, Phys. 116(9), 094303 (2014).

${ }^{34}$ C. Z. Zhao, Z. L. Bai, X. Y. Liu, Y. J. Zhang, B. S. Zou, and H. Z. Zhong, ACS Appl. Mater. Interfaces 7(32), 17623-17629 (2015).

${ }^{35}$ M. G. Panthani, V. Akhavan, B. Goodfellow, J. P. Schmidtke, L. Dunn, A. Dodabalapur, P. F. Barbara, and B. A. Korgel, J. Am. Chem. Soc. 130(49), 16770-16777 (2008).

${ }^{36}$ D. H. Jara, S. J. Yoon, K. G. Stamplecoskie, and P. V. Kamat, Chem. Mater. 26(24), 7221-7228 (2014)

${ }^{37}$ W. Liu, Y. Zhang, J. Zhao, Y. Feng, D. Wang, T. Zhang, W. Gao, H. Chu, J. Yin, and Y. Wang, J. Lumin. 162, 191-196 (2015).

${ }^{38}$ S. L. Castro, S. G. Bailey, R. P. Raffaelle, K. K. Banger, and A. F. Hepp, Chem. Mater. 15(16), 3142-3147 (2003).

${ }^{39}$ K. Gelderman, L. Lee, and S. Donne, J. Chem. Educ. 84(4), 685 (2007).

${ }^{40}$ Y.-K. Kim, S.-H. Ahn, K. Chung, Y.-S. Cho, and C.-J. Choi, J. Mater. Chem. 22(4), 1516-1520 (2012).

${ }^{41}$ M. Uehara, K. Watanabe, Y. Tajiri, H. Nakamura, and H. Maeda, J. Chem. Phys. 129(13), 134709 (2008).

${ }^{42}$ J. Huang, Z. Q. Huang, Y. Yang, H. M. Zhu, and T. Q. Lian, J. Am. Chem. Soc. 132(13), 4858-4864 (2010).

${ }^{43}$ W. H. Hu, J. Ludwig, B. Pattengale, S. Z. Yang, C. M. Liu, X. B. Zuo, X. Y. Zhang, and J. Huang, J. Phys. Chem. C 122(1), 974-980 (2018).

${ }^{44}$ M. Sakamoto, L. H. Chen, M. Okano, D. M. Tex, Y. Kanemitsu, and T. Teranishi, J. Phys. Chem. C 119(20), 11100-11105 (2015).

${ }^{45}$ C. J. Stolle, R. D. Schaller, and B. A. Korgel, J. Phys. Chem. Lett. 5(18), 31693174 (2014).

${ }^{46}$ Y. Zhou, S. Yang, and J. Huang, Phys. Chem. Chem. Phys. 19(11), 7471-7475 (2017).

${ }^{47}$ T. L. Li, C. D. Cai, T. F. Yeh, and H. S. Teng, J. Alloys Compd. 550, 326-330 (2013).

${ }^{48}$ X. B. Fan, S. Yu, F. Zhan, Z. J. Li, Y. J. Gao, X. B. Li, L. P. Zhang, Y. Tao, C. H. Tung, and L. Z. Wu, ChemSusChem 10(24), 4833-4838 (2017).

${ }^{49}$ K. Han, M. Wang, S. Zhang, S. L. Wu, Y. Yang, and L. C. Sun, Chem. Commun. 51(32), 7008-7011 (2015).

${ }^{50}$ P. Wang, C. P. Li, M. M. Wang, and Y. D. Jin, ChemPlusChem 83(12), 10881096 (2018).

${ }^{51}$ X. Y. Liu, G. Z. Zhang, H. Chen, H. W. Li, J. Jiang, Y. T. Long, and Z. J. Ning, Nano Res. 11(3), 1379-1388 (2018).

${ }^{52}$ M. D. Peterson, L. C. Cass, R. D. Harris, K. Edme, K. Sung, and E. A. Weiss, Annu. Rev. Phys. Chem. 65, 317-339 (2014). 